\title{
Testing Bilingual Speakers: Challenges and Potential Solutions
}

$\mathrm{It}_{\mathrm{t}}$ is estimated that $\sim 5$ million children attending grades $\mathrm{K}$ through 12 do not speak English with sufficient proficiency to follow the curriculum in English without receiving additional educational support. The number of these children increased by two million between 1996 and 2006, and constitutes $\sim 10 \%$ of the entire national school population. ${ }^{1}$ These students have been referred to with various acronyms such as NEP (nonEnglish proficient); LEP (limited-English proficient); and, most recently, ELL (Englishlanguage learner). As we end one decade and begin another in this millennium, the number of these students will most likely continue to increase. One of the most frequent concerns voiced by educators, administrators, and legislators is the over- or under-representation of these students in special education, hence the debate about language disorder versus language difference. The articles in this volume review this debate.

This first article, by Kohnert and Medina, focuses on research conducted over the last 30 years that distinguishes bilingualism from communication disorders. Findings conducted by using six electronic databases include 116 nonduplicated articles, with the first one published in 1978. A critical review of 64 articles indicates that the majority of these articles focused on bilingual sequential learners and development of their primary language (L1), which was most frequently Spanish. The authors found the database to be limited and of uneven quality. However, for the most part, performance on grammar, pragmatics, learning, and language processing measures sepa- rated typical second-language (L2) learners from their bilingual peers in their primary language (L1). In addition, the authors found that well-designed auditory and visual processing measures differentiated those who had language disorders from those who were developing normally.

In the absence of the "ideal" test or set of tests, a language sample can be a powerful tool to identify students who may have a language disorder. The second article in this volume, authored by Gutiérrez-Clellen and SimonCereijido, proposes methods to analyze spontaneous language samples to measure bilingual students' linguistic abilities (in this case, in both Spanish and English). The authors propose using a verb morphology composite measure in combination with a measure of mean length of utterance (MLU). Findings such as depressed MLU—combined with ungrammatical utterances and limited grammatical accuracy in use of articles, verbs, and clitic pronouns - in addition to omission of thematic arguments and limited use of ditransitive verbs may be among patterns that can signal a language disability. A rubric is offered to facilitate analysis of students' use of verb argument structures. The authors propose that the analysis should be used in both languages and supplemented with information from parent and teacher interviews and observation of the student's interactions with peers to appraise language proficiency. Potential differences in a student's use of language at school and home should also be considered in arriving at a final diagnosis. As with other authors in this volume, Gutiérrez-Clellen and Simon-Cereijido
${ }^{1}$ Communication Disorders and Sciences, Connie L. Lurie College of Education, San José State University, San José, California; ${ }^{2}$ Department of Hearing and Speech Sciences, University of Maryland, College Park, Maryland.

Testing Bilingual Speakers: Challenges and Potential Solutions; Guest Editor, Henriette W. Langdon, Ed.D.
Semin Speech Lang 2009;30:217-218. Copyright (C) 2009 by Thieme Medical Publishers, Inc., 333 Seventh Avenue, New York, NY 10001, USA. Tel: +1(212) 5844662.

DOI 10.1055/s-0029-1241720. ISSN 0734-0478. 
caution that one single measure is insufficient to arrive at a sound and fair conclusion regarding whether a student has a language-learning disability.

The connection between oral and written language has been long documented. Even though languages vary in structure and sound systems, there are some universals that bind the reading process across languages. The third article, by Gorman, focuses on this issue. Her article provides an overview of cross-linguistic universals in reading acquisition. It discusses how reading disabilities manifest themselves in various languages, and whether diagnostic and instructional approaches that are appropriate for English-speaking students are appropriate for ELL students. In conclusion, she states that several universal parameters are indicative of reading disabilities regardless of language structure and language combinations, including: (1) difficulty with phonological processing, (2) difficulty with working memory, and (3) poor performance on rapid automatic naming.

The fourth article, by Langdon and Wiig, provides an overview of existing bilingual tests (primarily in Spanish), including their development and contents. The latest list of available bilingual tests to speech-language pathologists (SLPs) practicing in the United States accommodates a wide range of client ages from preschool to adulthood. Like the previous authors, Langdon and Wiig acknowledge that no matter how carefully a test may have been designed to assess the bilingual student's or client's language skills, the results need to be combined with input from teachers, parents, observations, and results of language sample analyses to reach an informed judgment about whether language skills and progress are age appropriate or require intervention. In sum, the answer to "How does one differentiate a language disorder from a language difference or interim stages of language learning in bilingual language users?" cannot be determined simply with a test score or a set of scores. This situation is not likely to change dramatically in the years to come; we will continue to require careful, multifaceted analysis that we hope will become increasingly more accurate as research informs the selection of tasks that are sensitive in differentiating language disorder from language difference.

The last article in the series, by Westby, focuses on an aspect that is often neglected in the process of assessment and intervention of any student, whether monolingual or bilingual, even though it is required by law-that is, including the parent voice. Westby takes us through the guidelines we need to follow in involving parents and significant others in the process of assessing and planning intervention for children with various language-learning disabilities. Even though these individuals may not be proficient in English or familiar with the mainstream "American" way of parent participation, we need to hear their voice.

$$
\begin{array}{r}
\text { Henriette W. Langdon, Ed.D. }{ }^{1} \\
\text { Guest Editor } \\
\text { Nan Bernstein Ratner, Ed.D. }{ }^{2} \\
\text { Editor in Chief }
\end{array}
$$

\section{REFERENCE}

1. National Clearinghouse for English Language Acquisition and Language Instruction. The Growing Numbers of Limited English Proficient Students (1995/1996-2005/2006). Washington, D.C.: US Department of Education; 2009 